The Open Biomedical Engineering
Journal
Content list available at: www.benthamopen.com/TOBEJ/
DOI: $10.2174 / 1874120701610010001$

\title{
Retraction Notice: An Injectable Complex of $\beta$-tricalcium Phosphate Granules, Hyaluronate, and rhFGF-2 on Repair of Long-bone Fractures with Large Fragments
}

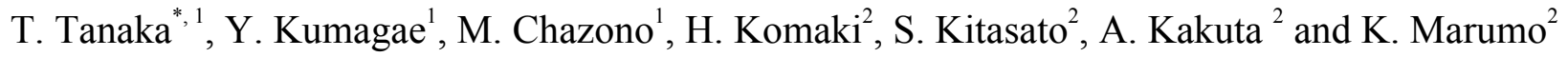 \\ ${ }^{I}$ NHO Utsunomiya National Hospital, Department of Orthopaedic Surgery, 2160 Shimo-Okamoto, Utsunomiya City, \\ Tochigi, 329-1193, Japan \\ ${ }^{2}$ Jikei University School of Medicine, Tokyo 105-8461, Japan
}

\section{BENTHAM SCIENCE DISCLAIMER}

It is a condition of publication that manuscripts submitted to this journal have not been published and will not be simultaneously submitted or published elsewhere. Furthermore, any data, illustration, structure or table that has been published elsewhere must be reported, and copyright permission for reproduction must be obtained. Plagiarism is strictly forbidden, and by submitting the article for publication the authors agree that the publishers have the legal right to take appropriate action against the authors, if plagiarism or fabricated information is discovered.

NOTE: As per Bentham Science's policy, the following article has been retracted upon approval of the Editor-in-Chief (Dr. Jason Carey) of "The Open Biomedical Engineering Journal".

Title: "An Injectable Complex of $\beta$-tricalcium Phosphate Granules, Hyaluronate, and rhFGF-2 on Repair of Long-bone Fractures with Large Fragments; Open Biomed. Eng. J., vol. 8; pp. 52-59."

Authors: T. Tanaka*, Y. Kumagae, M. Chazono, H. Komaki, S. Kitasato, A. Kakuta and K. Marumo

The above article is a near duplicate publication by the same team of authors (in a different order) that also includes duplicate figures of the article entitled "Use of an Injectable Complex of $\beta$-Tricalcium Phosphate Granules, Hyaluronate, and Fibroblast Growth Factor-2 on Repair of Unstable Intertrochanteric Fractures" Open Biomed. Eng. J., 2012, vol. 6, pp. 98-103. Bentham OPEN apologizes to the readers of the journal for not detecting this omission during the publishing process.

\section{REFERENCES}

[1] T. Tanaka, S. Kitasato, M. Chazono, Y. Kumagae, T. Iida, M. Mitsuhashi, A. Kakuta, and K. Marumo, "Use of an Injectable Complex of $\beta-$ Tricalcium Phosphate Granules, Hyaluronate, and Fibroblast Growth Factor-2 on Repair of Unstable Intertrochanteric Fractures", Open Biomed. Eng. J., vol. 6, pp. 98-103, 2012.

Received: December 29, 2015

Revised: January 5, 2016

Accepted: January 15,2016

(C) Tanaka et al.; Licensee Bentham Open.

This is an open access article licensed under the terms of the Creative Commons Attribution-Non-Commercial 4.0 International Public License (CC BY-NC 4.0) (https://creativecommons.org/licenses/by-nc/4.0/legalcode), which permits unrestricted, non-commercial use, distribution and reproduction in any medium, provided the work is properly cited.

\footnotetext{
* Address correspondence to these authors at the Department of Orthopaedic Surgery, NHO Utsunomiya National Hospital, 2160 Shimo-Okamoto, Utsunomiya city, Tochigi, 329-1193 Japan; Tel: +81 28673 2111; Fax: +81 28673 9117; E-mail: tanakat@e-utunomiya.hosp.go.jp
} 